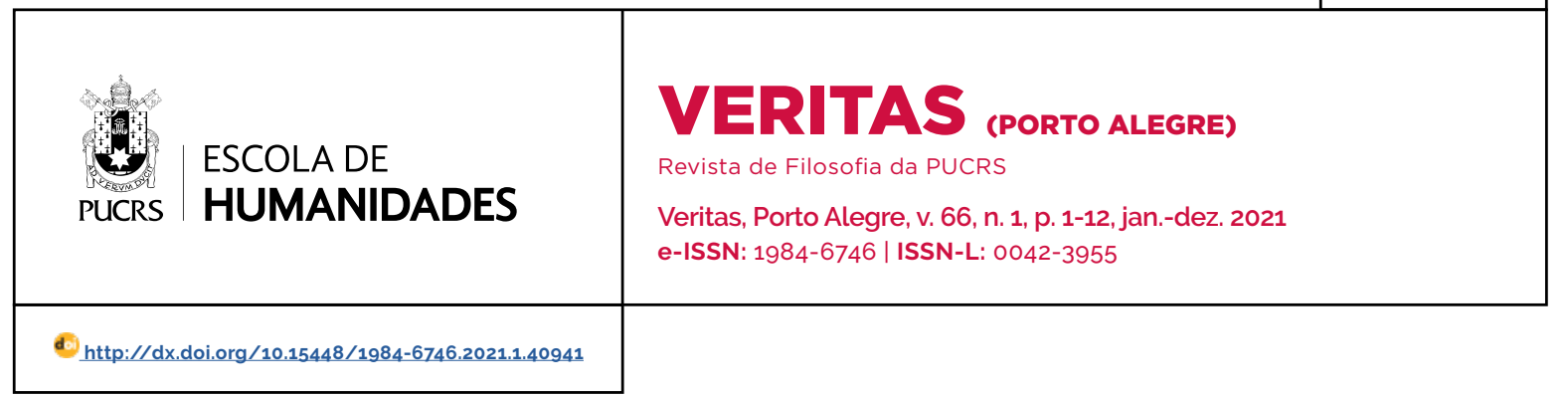

SEÇÃO: ESTÉTICA

\title{
A pré-aparência (Vor-Schein) artística como antecipação transgressiva no pensamento de Ernst Bloch ${ }^{1}$
}

\author{
The artistic pre-appearance (Vor-Schein) as transgressive anticipation in Ernst Bloch's \\ thought
}

La preapariencia (Vor-Schein) como anticipación transgresiva artistica en el pensamiento de Ernst Bloch

\section{Ubiratane de Morais Rodrigues ${ }^{2}$}

orcid.org/0000-0001-8101-9616 ubiratanerodrigues@gmail.com

Recebido em: 13 maio 2021. Aprovado em: 5 jul. 2021. Publicado em: 02 set. 2021.

\section{(c) (i)}

Artigo está licenciado sob forma de uma licença Creative Commons Atribuição 4.0 Internacional.
Resumo: O presente artigo tem como objetivo apresentar o conceito de pré-aparência (Vor-Schein) artística como antecipação transgressiva no pensamento de Ernst Bloch. Parte-se da hipótese interpretativa de que a estética utópico-concreta blochiana é sustentada na relação entre as categorias da pré-aparência (Vor-Schein) e da transgressão (überschreitung). O artigo problematiza as interpretações do conceito de pré-aparência (Vor-Schein) antes de expor as duas questões centrais da estética para Bloch: a aparência e a verdade da obra de arte. Segundo ele, a aparência da obra de arte não é a fonte do teor de utopia concreta presente na obra, mas sim a expectativa bem fundada nela. Assim, na expectativa bem fundada da obra, pode-se problematizar a questão da verdade na/da obra de arte, uma vez que a estética blochiana não abandona o mundo real, mas permanece imanente. Palavras-chave: Pré-aparência (Vor-Schein). Antecipação transgressiva. Estética.

Abstract: This article aims to present the concept of artistic pre-appearance (Vor-Schein) as transgressive anticipation in Ernst Bloch's thought. It starts with the interpretive hypothesis that the utopian-concrete blochian aesthetics is sustained in the relationship between the categories of pre-appearance (Vor-Schein) and transgression (Überschreitung). The article problematizes the interpretations of the concept of pre-appearance (Vor-Schein) before exposing the two central questions of aesthetics to Bloch: the appearance and the truth of the work of art. According to him, the appearance of the work of art is not the source of the content of concrete utopia present in the work, but rather the expectation well founded in it. Thus, in the well founded expectation of the work, one can problematize the question of truth in / of the work of art, since the blochian aesthetic does not abandon the real world, but remains immanent.

Keywords: Pre-appearance (Vor-Schein). Transgressive anticipation. Aesthetics.

Resumen: Este artículo tiene como objetivo presentar el concepto de pre-apariencia artística (Vor-Schein) como anticipación transgresiva en el pensamiento de Ernst Bloch. Se parte de la hipótesis interpretativa de que la estética blochiana utópica-concreta se sustenta en la relación entre las categorias de pre-apariencia (Vor-Schein) y transgresión (Überschreitung). El artículo problematiza las interpretaciones del concepto de pre-apariencia (Vor-Schein) antes de exponer las dos cuestiones centrales de la estética para Bloch: la apariencia y la verdad de la obra de arte. La apariencia y la verdad de la obra de arte. Según él, la aparición de la obra de arte no es la fuente del contenido de la utopía concreta presente en la obra, sino la expectativa bien fundada en ella. Asi, en la bien fundada expectativa de la obra, se puede problematizar la cuestión de la verdad en / de la obra de arte, ya que la estética blochiana no abandona el mundo real, sino que permanece inmanente.

Palabras clave: Pre-apariencia (Vor-Schein). Anticipación transgresiva. Estética.

Este artigo faz parte de minha tese de doutorado apresentada ao Programa de Pós-Graduação em Filosofia do Departamento de Filosofia da Faculdade de Filosofia, Letras e Ciências Humanas da Universidade de São Paulo no ano de 2020. A mesma teve financiamento de bolsa de estudo nivel doutorado da Fundação de Amparo à Pesquisa e ao Desenvolvimento Científico e Tecnológico do Maranhão - FAPEMA.

Universidade Federal do Maranhão (UFMA), Grajaú, MA, Brasil. 


\section{Introdução}

A estética de Ernst Bloch tem como categoria central a pré-aparência (Vor-Schein), compreendemo-la como uma estética em processo, aberta e sempre transgredindo os limites imanentes no sujeito e no objeto. Sendo aberta, possui elementos de possibilidades, e, por conseguinte, carrega em si a utopia; portanto, é estética transgressiva utópica. Seguimos a chave interpretativa de uma estética utópico-concreta no pensamento de Bloch que se sustenta na relação entre a categoria da pré-aparência (Vor-Schein) e da transgressão (überschreitung). Esta última categoria não é interpretada por Bloch no sentido vulgar de ação imediata, espontânea e sem conteúdo determinado. Parte-se do pressuposto de que a transgressão de limites implica um pensamento do limite como dilatação constante em perspectiva fronteiriça, onde cada ação prospectiva é dialeticamente permeada pelo caráter temporal do futuro imbricado na relação com o que ainda subsiste como inconcluso do passado, bem como sua relação com as tendências e latências da época presente. Transgressão dos limites impostos tanto pela faculdade da imaginação quanto pelas condições sociais do objeto a ser finalizado e pela resistência na matéria (mundo- pensamento-natureza) que precisam ser ultrapassados. Assim, pensa-se a transgressão como elemento antecipador de caráter prático-teórico funcionando na estética de Bloch como elemento de mediação entre o mundo (matéria) e o sujeito no esforço de garantir perfectibilidade ao objeto na imanência do mundo. Assim, apresentamos neste artigo, a compreensão do conceito de antecipação transgressiva como melhor interpretação para sustentar a estética blochiana do Vor-schein como uma estética utópica.

\section{Do conceito de pré-aparência (Vor-Schein)}

O conceito nodal da estética blochiana, pré-aparência (Vor-Schein), possui interpretações divergentes e complementares entre seus intérpretes, embora seja consenso entre os pesquisadores que o conceito de antecipação é central em seu pensamento. essas posições são retomadas em caráter metodológico para situar a chave interpretativa deste artigo no sentido de pontuar sua especificidade hermenêutica. destacam-se cinco interpretações: Pierre Furter em seu livro Dialética da esperança, quando passa à análise do conteúdo estético, interpreta a reflexão de Bloch sobre a arte como a-presentação e como relação entre a obra de arte e a totalidade visada. A singularidade de sua interpretação está em que "a obra de arte é presença (Schein) e, ao mesmo tempo, apresentação (Vor-schein)"; sua justificação é que "se fosse só presença, se a sua significação se esgotasse na sua contemplação - o que, aliás, acontece no caso da alienação estetizante -, a obra de arte não teria nenhum papel libertador, e não se entenderia a sua relação com a consciência antecipadora". 3

Jack Zipes propõe uma interpretação do Vor-Schein como iluminação antecipatória (anticipatory illumination). O primeiro argumento de Zipes é que Vor-Schein ou anticipatory illumination é "uma imagem, uma constelação, uma figuração bastante relacionada com as utopias concretas" 4 estreitamente ligada à função utópica da arte e da literatura na construção do mundo melhor. Esse termo, segundo o autor, explica melhor o que Bloch busca com o conceito de Heimat, compreendido como a casa ou pátria que todos almejamos. Vor-Schein como iluminação antecipatória fundamenta-se nos conceitos de ilusão e aparência reapropriados por Bloch de Kant e Hegel. Zipes demonstra como Kant, na Critica da Razão Pura, diferencia aparência (Erscheinung) de ilusão (Schein), concluindo que, segundo Kant, "a ilusão pode enganar através de sua natureza intangivel, e, ainda, de sua condição metafísica transcendental, que poderia servir como um corretivo para a realidade e apontar para um caminho em que se poderiam estender os limites 
da experiência". 5 Já em relação a Hegel, ele aponta que na Enciclopédia das Ciências Filosóficas, Hegel "demonstrou que a essência de uma coisa deve aparecer"6. E que há "uma dialética entre ilusão e aparência: a essência de um ser não é apenas ilusória como aparece, mas também é iluminada por meio de um brilho, que permite à essência do ser aparecer".7 É a partir destes dois conceitos e desses dois autores que - seguindo Burghardt Schmidt, Gerd Ueding, Arno Münster -, Zipes fundamenta sua interpretação do Vor-Schein como anticipatory illumination. Para ele, o Vor de Vor-Schein significa antecipação e não pré, e Schein deve ser diferenciado de ilusão e aparência. Iluminação, nesse caso, seria o melhor termo a ser utilizado, pois reflete melhor a relação do termo Vor-Schein com a arte. Zipes é categórico: "[...] 'antecipação' é claramente o que Bloch tinha em mente quando ele escolheu o Vor como prefixo para qualificar a natureza do Schein".

Fredric Jameson, em sua obra Marxism and Form, caracteriza o conceito de Vor-Schein como ontological anticipation (antecipação ontológica), embora esta interpretação apareça apenas duas vezes em todo o texto Ernst Bloch and the Future. ${ }^{9}$ Jameson não justifica a utilização deste termo; entretanto, seu escrito difere das outras interpretações quanto à relação entre arte e utopia em Bloch, não sendo sua preocupação analisar o conceito Vor-Schein. Todavia, existem duas importantes considerações que merecem destaque em seu escrito: a primeira é a caracterização de Bloch como hermeneuta, que, ao lado de Walter Benjamin e Herbert Marcuse, formariam um grupo de pensadores protagonistas, em versões diferentes, de uma hermenêutica marxista; a segunda, sua reflexão sobre uma "possivel" hermenêutica da obra de arte em Bloch em tensão com a religião.
Arno Münster é direto: o conceito de Vor-Schein funda uma estética da antecipação no pensamento de Ernst Bloch. Ele expõe a teoria estética blochiana situando-a ao lado de dois filósofos da arte do século XX: Adorno e Lukács. Münster analisa a estética em Bloch a partir de dois conceitos centrais: utopia (utopie) e antecipação (anticipation). Segundo ele, o esforço de Bloch foi garantir unidade a seu sistema categorial, o que o faz buscar uma estética da antecipação. Para Münster, "a teoria estética de Ernst Bloch é fundada sobre a dialética entre a potencialidade subjetiva (do criador) e as potencialidades objetivas (do material)". ${ }^{10}$ Münster responde à problemática da relação entre arte e utopia no próprio campo da dialética sujeito-objeto, sem recorrer à compreensão hermenêutica de uma possivel relação entre arte e religião, diferente assim da compreensão de Jameson. Ele também investiga a fundamentação do Vor-Schein na compreensão da filosofia alemã e traduz o conceito para o francês como pré-apparaître (pré-aparência) interpretando-o como anticipation. Ele divide sua análise linguística e semântica do conceito de Vor-Shein (anticipation) em dois momentos: "a) o 'vor' - conjunção de temporalidade que designa um "anterior" e, b) o 'Schein': aparência".11 Sua compreensão da estética blochiana é pautada, assim, na centralidade da anticipation e na hipótese de uma expressivité (expressividade), como afirma Münster:

$$
\begin{aligned}
& \text { a estética Blochiana é construida sobre uma } \\
& \text { só hipótese, uma só teoria da significação } \\
& \text { das grandes criações artisticas [...], a saber, } \\
& \text { nas grandes obras, de uma expressividade } \\
& \text { (expressivité) que é, na sua substância mesma, } \\
& \text { antecipação da utopia concreta. }{ }^{12}
\end{aligned}
$$

Gert Ueding é um dos comentadores de Bloch que mais influenciou as análises estéticas centradas no conceito Vor-Schein, principalmente por

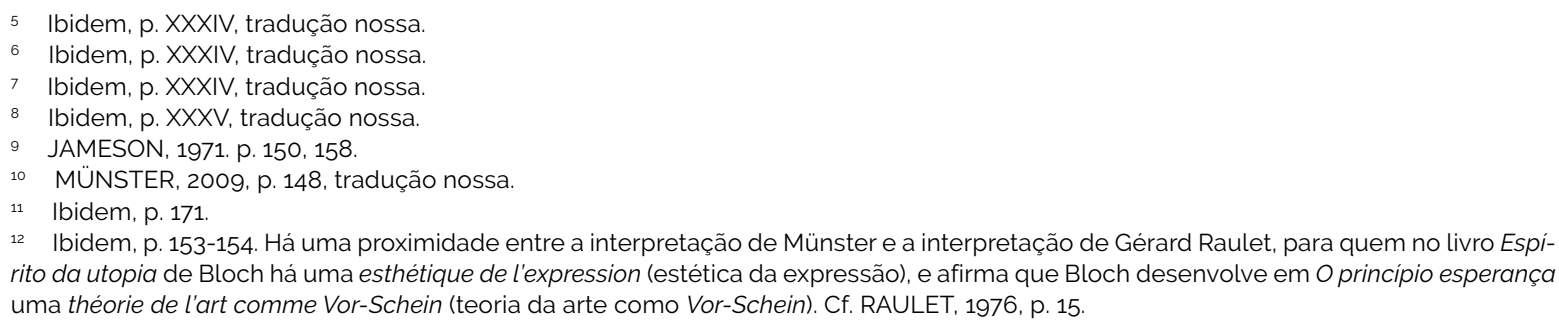


ter organizado em dois volumes um conjunto de escritos de Ernst Bloch relativos à estética sob o título de Estética da pré-aparência (Ästhetik des Vor-Scheins). ${ }^{13}$ Ueding afirma que a atividade estética e a obra de arte são elementos fundamentais da consciência utópica, e, portanto, parte do projeto utópico de Bloch. Segundo ele, o método de nosso autor é "ao mesmo tempo imediatamente concreto, fazendo intervir o sentido, e rigorosamente materialista"14, garantindo-lhe a possibilidade de resolver a questão de uma estética utópica mediante a organização estética de elementos extraestéticos e pelo conceito de antecipação. Somam-se às suas análises duas categorias fundamentais na compreensão da relação entre arte e utopia, a saber: a alteração (Verfremdung), que para ele é uma categoria central do Vor-Schein, e a organização dos conteúdos. Para Ueding, "só a organização estética de significações extraestéticas faz conhecer as antecipações que, sem ela, ficariam sem voz; ela faz conhecer o autêntico que se esconde na falsa consciência, e que the confere, aliás, sua força de sedução". ${ }^{15}$ Longe de uma apologia da forma estamos diante da capacidade estética da organização antecipatória dos conteúdos artísticos. Nesse sentido, para ele, são relevantes as considerações de Bloch sobre os meios estéticos, que levam Ueding a apontar uma importante contribuição de Bloch no campo da estética: seu rompimento com o esquematismo econômico, ou seja, a redução da cultura à economia, inviabilizando assim uma teoria do reflexo entre superestrutura e infraestrutura.

A estética do Vor-Schein em Bloch, segundo Ueding, é fundada em diálogo com Hegel. ${ }^{16} \mathrm{~A}$ partir desse diálogo, ele apresenta a arte como antecipação e como estímulo da práxis revolucionária17: "na medida em que a arte é tanto aparência como pré-aparência, [...] na medida em que, pela significação de suas cifras e de seus símbolos, ela visa sempre um além de si mesma, ela tem para a realidade social valor de incitação".18 Percebe-se, assim que a arte em Bloch não permite uma interpretação do reflexo imediato, pois a realidade, que é fragmentada e em constante devir, tem na arte como fragmento um laboratório de possibilidades, e isso traz uma consequência importante na interpretação de Ueding: para ele o fragmento é a categoria central da filosofia da arte de Bloch. ${ }^{19}$ Visto que "as significações estéticas utópicas aparecem como fragmentos", e ainda, "o Vor-Schein é fragmento, com uma abertura dinâmica, finalizada, uma forma que muito nitidamente transcende seus próprios limites". 20 A relação entre arte e utopia, ou ainda, uma alternativa à estética utópica em Bloch proposta por Ueding passa assim pela análise da estética do Vor-Schein como estética do fragmento.

\section{A pré-aparência (Vor-Schein) artística}

Diante desse quadro hermenêutico, ${ }^{21}$ propõe-se uma interpretação estética da categoria do Vor-Schein como antecipação transgressiva sem desconsiderar a importância das interpretações acima. Entretanto, não se compreende o conceito da pré-aparência (Vor-Schein) em Ernst Bloch pela chave do Idealismo, mesmo reconhecendo a influência do Idealismo alemão em sua obra; tampouco é possivel reduzir sua estética somente ao marxismo ocidental. Neste sentido, far-se-á o percurso interpretativo de seu pensamento estético na chave do processo em que se encontra o próprio pensamento de Bloch. Para tanto, parte-se da problematização feita por Bloch de duas questões centrais da estética: a aparência e a verdade da obra de arte. Ressalta-se que Bloch

Além dessas considerações acima, existem também as interpretações em relação à estética de Bloch que não passam diretamente por um tratamento da questão conceitual do Vor-Schein, mas de importância significativa para elucidações conceituais do pensamento de Bloch: Francesca Vidal, José Jimenez, Heinz Kimmerle, O. K. Werckmeister e Javier Contreras. 
não tem em vista uma arte de caráter efêmero, nem a fruição exacerbada do espectador moderno ávido de experiências estético-sensiveis; a obra de arte não tem só o assombro do deleite, mas perdura no tempo, e é capaz de continuar jovem e convocativa, uma vez que para ele a arte não é comida: metáfora da temporalidade da obra de arte que nos abre inclusive a possibilidade de interpretar a obra de arte como tempo.

Esta metáfora direciona o diagnóstico histórico do jogo da aparência e sua relação com a verdade, seja em O princípio esperança, seja em Tübinger Einleitung in die Philosophie. Segundo Bloch, os empiristas, os racionalistas e os teólogos deram tratamento menor à arte, quando não a proscreveram totalmente de seus sistemas. Eles abordaram de forma precária a obra de arte, argumentando que a arte é ineficaz para o conhecimento da verdade e/ou da fé, ou ainda, sustentando o problema da ilusão e de sua aparência. Destarte, um dos primeiros problemas a se enfrentar é o da ilusão estética na própria aparência da obra de arte, dada sua associação ao não verdadeiro, ao ilusório e ao que desvia do caminho para a redenção. Entretanto, qual é o tratamento da concepção de aparência dado por Bloch? Quanto ao jogo entre aparência e verdade na obra de arte, ele pode ser seguido em duas direções, uma é o debate com Schiller sobre o jogo, na esteira de Kant, a outra é seguindo Freud. A primeira é a mais clássica e comentada, dado que o próprio Schiller é citado por Bloch. Todavia, não se descarta a direção para Freud, pois o escrito 0 poeta e o fantasiar, já trabalhado acima, era de conhecimento de Bloch e foi comentado por ele.

Embora seja pela aparência que a obra de arte se manifeste, ela não é a fonte do teor de utopia concreta presente na obra, mas sim a expectativa bem fundada nela. Por isso sua preocupação em desviar-se da estética da contemplação, da estética puramente embelezadora do real estático, preocupação que aparece na metáfora da temporalidade pós-fruição da arte. ${ }^{22}$ As obras de artes que são frutos dos sonhos diurnos tor- nam-se "um belo que ganhou forma", visto que como fantasia objetiva bem direcionada eles são os responsáveis pelas obras utópicas concretas, principalmente quando são levados às últimas consequências. A questão para nosso autor é saber o que pode haver para além desse "belo que ganhou forma", ou ainda, saber se a aparência da obra revela algo a mais que sua apresentação sensivel, jogo da aparência como jogo da beleza. A aparência surge de início como problema, "um jogo que pode até ser extremamente artístico, mas que, diferentemente do infantil, não prepara para nada sério nem significa nada sério"23. Essa exigência está diretamente ligada ao diálogo com Freud em seu texto O poeta e fantasiar. Em Freud há um jogo tanto na fantasia poética como na atividade de brincar das crianças; para estas, a brincadeira é uma atividade séria, que se opõe à realidade. O jogo da imaginação em Bloch difere daquele da criança porque a fantasia não está em total oposição à realidade, mas somente à má realidade, ao existente ruim, e a sua função é "pintar" uma realidade melhor com elementos concretos desta, ainda que revelados em forma de fragmento posterior. O mundo levado a sério pelas criações utópicas-concretas é um mundo não existente ainda, podendo ser idealizado nas brincadeiras, mas distinto da realidade infantil. Bloch não perde de vista que a arte tem um caráter de jogo, que a imaginação joga com o real, mas descarta aquela afinidade referida por Freud entre o brincar e o fantasiar. Ora, nesse jogo de aparência, a busca é por algo autêntico.

Bloch parte das artes visuais para examinar o teor de verdade das obras de arte. a pintura é o primeiro objeto de análise e a primeira a ser descartada para dar lugar à arte poética. Ele segue, a princípio, a hierarquia das obras de arte proposta por Hegel em seus Cursos de Estética, pois acredita, metodologicamente e de início, que a arte poética tem mais qualidades e condições de suscitar a pergunta pela verdade que a pintura. A arte poética também é limitada e, como a pintura, é descartada nessa tarefa de manipu- 
lação do jogo da aparência na obra em vista da verdade estética. Caberá à música essa estação de partida e chegada da pergunta/resposta pela verdade. Há nesta busca a certeza do distanciamento entre arte e verdade. Assim, nosso autor busca argumentar desde a aparência e seu jogo na obra de arte uma estética utópica-concreta.

A aparência artística assim se depara com o problema filosófico da verdade. Contudo, toda arte quer mesmo dizer a verdade? O problema da verdade é uma questão para os artistas ou para os filósofos? Na relação entre a produção criativa e a verdade, Bloch investiga o que a arte comunica, e não é por acaso que ele classifica a reflexão estética em seu livro Experimentum Mundi24 na categoria da comunicação. O que comunica a arte? Preocupado em não fundamentar a comunicação da ilusão pela arte, Bloch problematiza a ilusão na aparência, tendo destaque nessa relação beleza-comunicação e verdade dois filósofos: Schiller e Hegel. Bloch parte de duas questões centrais para sua reflexão: "I...] O que representa [...] a no mínimo profética sentença de Schiller de que aquilo que aqui percebemos como beleza um dia virá ao nosso encontro como verdade?", e ainda, "O que representa a sentença de Plotino e depois de Hegel de que a beleza seria a aparição sensivel da ideia?".25

Essas perguntas, por um lado, norteiam de certa maneira a investigação de uma estética blochiana, mas apresentam, por outro, um falso caminho para a interpretação de sua estética, a saber: compreendê-la pelo caminho da estética idealista. Embora Francesca Vida ${ }^{26}$ tenha afirmado que a estética de Bloch se encontra na tradição da estética idealista, ela localiza essa filiação no momento em que o debate estético passa pela questão da subjetividade e de sua relação com o mundo. É no momento de pensar as regras sem regras para o ordenamento da subjetividade es- tética que Bloch poderia ser inserido na tradição do idealismo alemão, ou ainda, na medida em que acredita na esperança, ou na utopia concreta como um Ideal possivel-real. Vidal reconhece que a preocupação de Bloch já se diferencia das tentativas de oferecer regras ao espirito, já não é sua preocupação debater entre um saber superior (razão) e um saber inferior (sensualidade), o qual é debatido pelas estéticas do século 18 no confronto com Descartes, por exemplo. Se o idealismo-romantismo alemão influencia Bloch, não é menos verdade que ele se apropria consideravelmente desses autores para pensar a arte.

Dito isto, deve-se acrescentar que, ao se apropriar desses filósofos e literatos, Bloch não reivindica pertencimento a essa tradição, mas no debate critico e proficuo ele recolhe as heranças filosóficas daquilo que ainda não veio a ser, aquilo que ainda é mobilizador de potencialidades utópicas. A estética de Bloch não deve ser lida sem o olhar para estes filósofos, na mesma medida em que não se pode simplesmente colocá-lo ao lado deles como mais uma filosofia do Idealismo. A estética blochiana se insere inequivocamente na tradição marxista heterodoxa ${ }^{27}$ dialeticamente perpassada pela história da arte e pela filosofia em vista de uma utopia concreta e de uma estética como moldura da sociedade livre e sem classes. Inversamente à estética da mera aparência contemplativa ou puramente instrumental, ela está inserida no pensamento marxista e ligada não só à atividade espiritual do gênio, mas ao trabalho humano. Nestes termos, pode-se compreender a citação abaixo:

O meio da primeira humanização foi o trabalho, o solo da segunda é a sociedade sem classes. sua moldura é uma cultura cujo horizonte é circundado exclusivamente por conteúdos de esperança bem fundada, como sendo ser-em-possibilidade mais importante, o ser-em-possibilidade positivo. ${ }^{28}$

\footnotetext{
24 Especificamente nos capítulos 42 "Allegorischer Vor-Schein in der Kunst ohne Illusion" e 43 "Symbolischer Vor-Schein in Metareligion ohne Aberglauben" In: BLOCH, 1985, p. 196-212.

$25 \mathrm{BLOCH}, 2005$, v. 1, p. 208.

26 VIDAL, 2012, p. 13. Ou ainda, em uma análise que coloca Bloch como estética metafísica. Também conferir o verbete Vor-Schein. In DIESTSCHY, Beat; ZEILINGER, Doris; ZIMMERMANN Rainer (hrsg.): Bloch-Wörterbuch: Leitbegriffe der Philosophie Ernst Blochs. 2012. p. 660; onde Werner Jung reconstrói na linha de Gert Ueding a estética de Bloch, associando-o ao idealismo alemão de Kant, Schelling. Hegel, sem as mediações necessárias, como o fez Francesca Vidal; contudo, traz uma importante análise do Vor-Schein como verdade do ser.

27 O argumento de Vidal não se refere somente a Bloch, mas ainda a Adorno. para ela, ambos estão na tradição idealista quando intervém na questão da autonomia da estética e sua posição social. Por isso ela salienta ser preciso pensar a estética de Bloch em relação a Theodor W. Adorno, Walter Benjamin e Georg Lukács.

$28 \mathrm{BLOCH}, 2005$, v. 1, p. 208, grifo nosso.
} 


\section{A verdade da obra de arte}

Essa digressão ao argumento da filiação idealista de Bloch serviu para retomarmos a questão da verdade na obra de arte, cientes de que a estética que ora se analisa é de caráter utópico, materialista e dialético. Dessa perspectiva, a verdade toma um espaço considerável na fundamentação da estética de Bloch, não como preocupação puramente teórica cognoscitiva, mas em uma tentativa de ligar a arte ao concreto do mundo. O problema da verdade para Bloch não é em sua filosofia uma questão moral, tampouco uma questão de verdade da lógica formal, em que S é P, ou seja, onde "[...] o sujeito refere-se no julgamento pela cópula de seu predicado".29 $\mathrm{A}$ verdade lógica na filosofia de Bloch é aquela onde $S$ não é $\mathrm{P}$, ou melhor, $\mathrm{S}$ ainda não é $\mathrm{P} .{ }^{30} \mathrm{Como}$, nessa sentença, o sujeito ainda não encontrou seu predicado, ela não absolutiza verdades e infertiliza o pensamento acerca do verdadeiro e do belo. Não há identidade entre o sujeito que ainda está em processo e o real imediato, nublado pela ideologia e pela incompreensão da obscuridade do agora por parte do sujeito. Se se reduzir a verdade ao encontro lógico imediato do sujeito com o objeto, anula-se a dialética do processo na qual estão imersos tanto o sujeito quanto a matéria (objeto). A verdade neste caso é apenas formal, sem um conteúdo substancial-dinâmico; não só a relação de identidade entre ser e pensar, apontada por Bloch desde Parmênides, impede uma abordagem mais proveitosa do conhecimento em vistas à verdade, como também, na modernidade burguesa a luta da análise da verdade contra a ideologia, ou, ainda, o espelhamento entre a infraestrutura e a superestrutura, além de uma tomada de posição em relação à verdade, ora como vinculada ao sujeito, ora ao objeto. Para nosso filósofo, a verdade do sujeito e a verdade de sua história estão abertas no front do mundo ${ }^{31} \mathrm{~A}$ verdade, no mundo em processo, objetivamente falando, não pode ser encerrada pelos fatos, como diz Bloch:

A abertura objetiva é, acima de tudo, a mesma coisa que a variabilidade objetiva; de acordo com a qual a verdade de uma certeza não é, em última análise, verificada pelo conteúdo observado de fatos, mas pela possivel prática de mudança de processos e seus resultados. ${ }^{32}$

É na mediação com o mundo que se resolve o problema da verdade, não como o materialismo mecânico criticado por Bloch, nem pela via da abstração pura do pensamento.

Quanto à verdade estética e à verdade religiosa, Bloch estabelece cuidadosamente as distinções entre elas, salientando que tanto a arte quanto a religião inclinaram-se em direção ao padrão de verdade que a ciência utiliza, fazendo com que ambas recaissem no mesmo erro. Não se podem estranhar, nesse caso, as perguntas por provas e verificações de falseabilidades na arte e na religião por aqueles que se arvoram, e são considerados, cientistas. Contudo, a arte, no seu embate com a verdade e sua justificação para o mundo, é menos convincente que a religião. Visto que a verdade desta é retirada acima da razão, verdade transcendente ao mundo, enquanto a arte, quando expõe sua verdade, aparece no âmbito do prazer, e, segundo a tradição kantiana, prazer desinteressado. Entretanto, para Bloch a arte é

[...] muito mais feliz, maçãs douradas em tigelas
de prata, e o palco, diz o fruidor, é iluminado ape-
nas à noite e apenas enquanto se joga nele, isso
permite que a arte tenha mais traços pré-cienti-
ficos ou extra-científicos, até mesmo memórias,
sem desencantamento aqui estragando o jogo. ${ }^{33}$

Mesmo diante desse muito mais feliz, na relação entre a verdade e a obra de arte, os filósofos, seus intérpretes, a consideraram uma mentira necessária, como no caso da crítica nietzschiana, para tornar a vida mais suportável, fazendo encobrir-se a arte "[...] com o véu do pensamento impuro".34 Bloch lembra ainda das considerações de Francis

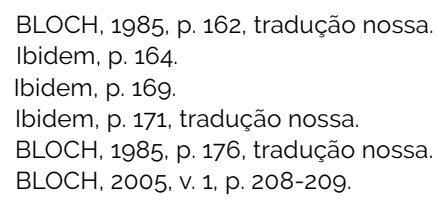


Bacon sobre as idola theatri tradicionais. Na visão dos filósofos, segundo o nosso autor, os artistas estão condenados à mentira e à ilusão. Não seria, por conseguinte, preocupação dos artistas o jogo entre arte e verdade na aparência da obra, mas unicamente com a aparência em si da obra. O ponto central desta crítica filosófica em relação à verdade da obra de arte se aprofunda no Iluminismo. Sabe-se que esse debate entre obra de arte e verdade tem suas raízes em Platão e sua crítica à mimese pautada em sua famosa e contraditória expulsão dos poetas da República. Entretanto, Bloch se atém ao lluminismo, em que, segundo ele, "[...] como um todo se encontram premissas para a antítese 'arte-verdade', e elas colocaram a fantasia artística sob suspeita a partir do senso para os fatos". 35 Ele distingue dois tipos de objeções: a primeira são as dos empiristas, a segunda são as objeções dos racionalistas, todas contra a arte.

O questionamento de um matemático francês depois da apresentação da peça Ifigênia de Racine exemplifica, em parte para Bloch, as posições do racionalismo contra a arte: "[...] Qu'est-ce que cela prouve? Por mais que essa pergunta pareça rasteira e afetada pelo fetichismo da especialização, ela se situa, como pergunta puramente racional, na escola própria e representativa da estranheza da arte, equivalente à empírica". ${ }^{36}$ Segundo nosso autor, a estética é omitida nos grandes sistemas racionalistas, vide Descartes, Espinosa ${ }^{37}$ e Leibniz como exemplos de tratamento da arte em seus sistemas de ideias filosóficas, só usada quando necessária à fundamentação de suas teorias, como no caso do último em relação à harmonia na música. Baumgarten, a quem é dirigida a responsabilidade de ter convertido a estética do racionalismo em disciplina filosófica em seu início, não escapa à crítica de Bloch, para quem a estética:
[...] teve um inicio bem esquisito: começou com um pronunciado menosprezo do próprio objeto [Gegenstand], até desculpando a sua existência. O objeto [Gegenstand] estético era unicamente a capacidade cognitiva chamada baixa, efetiva na percepção sensivel e em suas imaginações. E ainda que nesse âmbito beleza representasse perfeição, em termos de valor ela não era comparável à completa clareza do conhecimento conceitual..$^{38}$

Em geral, para Bloch, houve uma desqualificação racionalista e empirista da arte; inclusive, esse "ódio à arte" (Kunsthass) também chegou à religião. Não há nesta uma desqualificação pela razão, mas pela fé, embora ele acrescente que "pelo menos como algo espiritualmente verdadeiro".39 A consequência dessa relação entre arte-religião é a iconoclastia: "O teor do veredito é que a beleza desencaminha para a superficie, esbugalha-se no lado externo sem essência e assim desvia da essência das coisas".40 A religião judaico-cristã retira a dimensão estética não do logos, mas da fé através do mandamento bíblico: "não farás para ti imagem nem qualquer similar ao que está lá em cima no céu, nem ao que está aqui embaixo na terra, nem ao que está na água sob a terra", ${ }^{41}$ provendo assim, "[...] a senha para a iconoclastia da invisibilidade de Javé, a partir da proibição de qualquer idolatria".42 A arte impediria, nesses termos, o caminho do devoto a Deus, e, por ser luciférica e desviadora da Verdade celestial, não tem espaço na religião; sendo engano e ilusão, sua aparência é uma blasfêmia. Na expressão de Bloch, o horror pulchri predominou tanto no catolicismo quanto no protestantismo. Este, que é radicalmente contra qualquer expressão visivel de Deus e de qualquer adoração de imagens, prioriza a verdade na palavra. Ademais, seja nas formas da razão, seja nas formas da fé, as objeções à arte sempre existiram. Entretanto, 
mesmo diante de todas as criticas e resguardados os juizos morais e políticos, é preciso salientar o empenho da religião cristã, especialmente da vertente católica, em financiar e difundir grandes artistas e suas produções.

Deve-se entender a interdição das imagens somente no sentido religioso? No tempo de Bloch também houve um momento de interdição das imagens e uma espécie de iconoclastia: a interdição das imagens à juventude revolucionária. A arte era designada como perda de tempo, enquanto desperdícios de esforços, uma outra espécie de iconoclastia, em que a arte aparecia "[...] como se fosse exclusivamente uma fábrica de mentiras", 43 o que parecia ser um fim da arte. Isso ocasionou inclusive uma dificuldade de posicionamento diante das próprias Vanguardas artísticas históricas, uma vez que elas passaram pelo problema de legitimação e uma espécie de iconoclastia no interior da própria produção artística. O maior expoente foi, segundo Bloch, o expressionismo, que significou "[...] o último exemplo do que se poderia chamar uma plenitude artística". 44 A época de Bloch foi uma época de mudança social, ele fez um diagnóstico em um momento em que a arte não tinha mais a segurança institucional que a sustentava. Nessa época de transição, sua expressão o verniz rachou (Der Lack der Oberfläche) expressa não só um passado, uma quebra na tranquilidade do estatuto da arte, como também o nascimento de um fragmento, que anuncia um novo que não está presente ainda e nem esteve no momento da produção da obra. segundo a tese de Bloch, diante desse contexto,

[...] a teoria estética de uma arte possivel de ocupar este vazio pode refletir as ameaças que o preconceito classicista sempre teve nas épocas de obras de arte bem-sucedidas, ou, pelo contrário, nunca capaz de ir além de si mesmo. Dentro da categoria setorial da arte se anuncia por ela mesma, promovendo a pré-aparência (Vor-Schein) acima da aparência - no lugar da aparência - uma estética sem ilusão significada e rompendo com toda relação da arte meramente contemplativa. ${ }^{45}$

Diante da mudança de época, as obras apontam um desejo daquilo de que se sente falta, que é urgente no humano. a pré-aparência se manifesta inclusive em obras que têm caráter pessimista, nesse contexto seja no caso de um Samuel Beckett ou de um Musil (Esperando Godot e O homem sem qualidades, respectivamente). Mesmo uma espera objetivamente não alcançável em Beckett move a centelha subjetiva de um ainda-não, se a menor pré-aparência em Beckett contribui na pré-aparência de Musil, Bloch destaca que, mesmo que a peça de Beckett sinalize uma inutilidade da espera, ela ainda assim tem um lado de pré-aparência. Musil não é só pessimista; como diz Bloch, sua obra vislumbra uma transformação:

[...] a indeterminação vazia, cheia de expectativas mas constantemente negativa, cria ao mesmo tempo as condições para um resultado que permanece aberto para tentativas de ação que constantemente interrompem de suas experiências por suas insuficiências. ${ }^{46}$

A falta que move a expectativa, que faz surgir um fragmento de esperança é radicalizada desde a peça de Brecht Mahagonny e a frase chave da ausência: "falta Algo!" (Etwas fehlt!). Essa é a chave de abertura reflexiva sobre a expectativa que acompanha Bloch em toda sua jornada filosófica. Mesmo que o tom dessa peça pareça niilista, já que no final ninguém pode fazer nada por ninguém (Können uns und euch und niemand helfen), ${ }^{47}$ a peça não tem esse teor puramente pessimista, mas contém uma dose significante de pré-aparência. Não poder fazer nada por ninguém não é pura contemplação do mal, embora Bloch reconheça que só posteriormente Brecht chame o espectador à reflexão.

Na relação arte-verdade, a expectativa bem fundada garante o teor de verdade da obra, devendo a pré-aparência ser buscada inclusive nessas obras onde rondam as sombras do niilismo

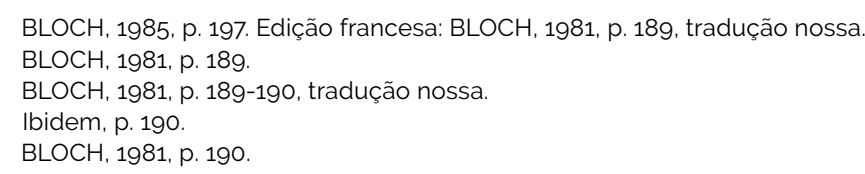


e pessimismo. Uma vez que mesmo nelas a aparência foi por vários caminhos combatida, omitida e deturpada. Em última instância, é a disputa entre o logos e a beleza que gira em torno da questão fundamental pela verdade da obra de arte. A arte não teria como nos levar à essência das coisas, embora seja consenso na história da arte que não seja essa a finalidade. Assim, ao contrário do que disseram os filósofos, os artistas, segundo Bloch, preocuparam-se com a questão da verdade, e há neles uma seriedade não solipsista, mas um constante contato com o mundo. Não obstante, eles não resolveram a questão da verdade, mas seus trabalhos ampliaram e precisaram melhor essa questão; mesmo não alcançando aquela verdade pretendida pelos filósofos, a obra de arte se diferencia segundo a finalidade cognoscitiva, o que implica que a arte tem algo para nos dizer que é diferente das fontes históricas e científicas. A respeito dessa ampliação, é na arte realista que Bloch se fundamenta para reforçar seu argumento, pois nos poetas realistas "[...] o belo quer ser suficientemente verdadeiro também no nivel metafórico. Isto não só no nivel da convicção sensitiva, mas também no nivel francamente aberto das relações sociais, dos processos naturais".48

A poesia de Homero, rica em detalhes reais, é um exemplo para Bloch ao lado de Shakespeare, Goethe e Keller para significar o compromisso da arte verbal realista com a verdade. No entanto, não é nos artistas nem nos filósofos que se deve buscar a verdade do belo, mas nas próprias obras que nos desafiam a esta tarefa. É preciso tensioná-las o máximo possivel para formular o argumento sobre a verdade estética da obra de arte - este é o método de Bloch, que o permite dizer:

A Ressurreição de Lázaro de Giotto, o Paraiso de Dante, o céu na parte final do Fausto: que relação eles têm - para além de qualquer realismo nos detalhes - com a pergunta filosófica pela verdade? Sem dúvida, eles não são verdadeiros no sentido de toda a noção de mundo adquirida por nós. Mas o que significa, então, de modo legítimo, com referência ao mundo, a extraordinária impressão causada pelo conteúdo-forma dessas obras, que não pode ser separado delas?49

A estética de Ernst Bloch, sendo determinada pelo conteúdo, não negligencia a forma, mas trata forma e conteúdo como par dialético na totalidade da obra, "privilegiando" o conteúdo. Diante das questões acima, ele retoma a pergunta do matemático francês depois da apresentação da Ifigênia, de Racine. Porém, em outro nível do "Qu'est-ce que cela prouve?"; ele reelabora e desloca a pergunta pela verdade da arte, indicando que a aparência bem-acabada aparece nos romances justamente quando a obra ultrapassa seu próprio tema, quando ela, ao ser realista, não é vulgar, não abandona o mundo real, permanece imanente mesmo diante e por causa mesmo de sua fabulação e exageração na aparência. Por tratar a pergunta pela verdade da obra de arte em outros termos que não aqueles do racionalismo, do empirismo ou da iconoclastia religiosa, a questão ganha outra dimensão, segundo nosso autor:

a pergunta pela verdade da arte se transforma, no nivel filosófico, na pergunta pela possibilidade ocasionalmente existente de representação da bela aparência, na pergunta pelo seu grau de realidade em meio à realidade de modo algum unidimensional do mundo, na pergunta pelo lugar do seu correlato como objeto. ${ }^{50}$

A estética é descolada da pura contemplação para uma estética cujo conteúdo tenha um correlato possivel-real, uma estética de cunho dialético materialista. Se há na arte algo de utópico, se há uma função utópica na arte, então essa pergunta pela verdade passa pelo possivel-real, por sua ontologia transgressiva fundada no ser-sendo-em-possibilidade. Concedendo assim à aparência artística não o status de pura ilusão, mas o estatuto ontológico de concretude cujo brilho aponta para mais-além, cujo correlato é o possivel-real no presente aberto e inconcluso. Ora, se a pergunta é deslocada, a resposta também é outra; se não há uma unidimensionalidade na pergunta, também não há na resposta.

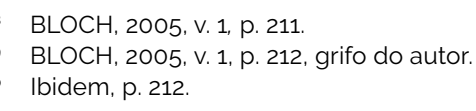


[...] em toda parte, a aparência artística não é mera aparência, mas uma significação envolta em imagens, designável somente mediante imagens, do que foi impulsionado para a frente, em que a exageração e a fabulação representam a importante pré-aparência do real, que circula no próprio existente em movimento, uma pré-aparência que pode ser representada especificamente de modo imanente-estético. ${ }^{51}$

Com efeito, a estética do Vor-Schein aparece assim atrelada à resposta da questão da verdade na obra de arte e sua correlação direta com a aparência artística. Isso leva Bloch a assumir a tese de uma estética cujo teor de transcendência imanente reverbera a utopia concreta. A obra não é uma imagem por imagem, não está encerrada, estática, mas aberta, há nela uma pré-aparência que existe no real, no mundo cujas terminações passam pela matéria aberta e em processo. A não compreensão da pré-aparência na obra liga-se tanto às determinações subjetivas quanto às objetivas, e a alienação cumpre nesses termos um importante papel no embotamento dessa pré-aparência. A arte manifesta a pré-aparência através das infinitas possibilidades que esta permite a seu objeto: sua possibilidade está no fato de que a arte leva seus temas até o fim, sendo que "a própria pré-aparência é o que pode ser obtido pelo fato de a atividade do levar-até-o-fim ocorrer no espaço dialético aberto, no qual qualquer objeto [Gegenstand] pode ser representado esteticamente".52 Pelo fato de estar bem fundada e em relação com o possivel-real, a pré-aparência garante à arte uma verdade concreta, pois aponta para um correlato material presente e para uma possibilidade-real futura, portanto utópica. Nesses termos, a estética de Bloch garante um estatuto ontológico à obra de arte fundada no possivel-real, sustentando a necessidade da aparência da obra e salvando esta aparência da ignomínia do racionalismo e da religião. A antecipação daquilo que o tema só anuncia vem em forma de beleza ao nosso encontro na obra de arte como

BLOCH, 2005, v. 1, p. 212, grifo do autor.

Ibidem, p. 212, grifo do autor.

BLOCH, 2005, v. 1, p. 212-213.

Ibidem, p. 213

Ibidem, p. 213; BLOCH, 1981, p. 211.

BLOCH, 2005, v. 1, p. 214, grifo do autor. pré-aparência livre de ilusão, aparência como pré-aparência, pois "[...] tudo o que aparece na imagem artística foi aguçado ou reforçado numa firmeza de decisão que, mesmo apenas raramente manifestada pela realidade experiencial, é perfeitamente inerente aos temas".53

A pré-aparência é fundamento ontológico da arte, cujo conteúdo de verdade é inerente à aparência da obra, aparência bem fundada. Justamente pelo fato de a arte levar até o fim em figuras, situações, ações individuais do mundo, sempre no universo do próprio real ela "[...] é não-ilusão, pois ela atua no prolongamento daquilo que se tornou existente, na caracterização mais adequada de sua forma",54 portanto, sem transcendência além-mundo. Diferente da religião, a pré-aparência da arte permanece imanente, e este é um problema que persegue Bloch desde seu primeiro livro: "[...] como poderia o mundo ser plenificado sem explodir e desaparecer apocalipticamente, como na pré-aparência religiosa cristã [...]".55 A arte e a religião se diferenciam quanto à pré-aparência na medida em que a primeira só arredonda seu objeto, plenifica individualmente cada coisa, não há apocalipse nem salvação no paraíso, enquanto a religião cristã busca a plenificação da totalidade, um novo mundo, uma nova sociedade, uma nova ordem via chave apocaliptica. Nesse sentido, põe-se inevitavelmente a pergunta: como a pré-aparência resolve a pergunta estética pela verdade na obra de arte? A reposta de Bloch é que "[...] a arte é um laboratório e igualmente uma festa de possibilidades efetivadas, juntamente com as alternativas nelas experimentadas, sendo que tanto a execução quanto o resultado acontecem no modo da aparência bem fundada [...]".56

O mundo é o lugar da resposta última dessa pergunta, é nele que podemos encontrar as antecipações e a pré-aparência plenificada. Se de início Bloch, provocativamente, coloca a arte verbal como lugar privilegiado para a verdade estética - por exemplo, a poesia - agora ele 
aponta definitivamente onde buscar a resposta a esta questão: "todavia, não é na arte verbal $e$ sim na sociedade que se decide se o clamor por plenitude - pode-se designá-lo como a oração ateia da poesia - pode até certo ponto assumir contornos práticos e não ficar restrito apenas à pré-aparência estética".57 Mas aqui não se pode confundir essa sociedade com o fundamento último da obra de arte, porque toda a estética de Bloch tem por fundamento o ontológico, não o social. Isso é fundamental para entendermos como a estética de Bloch se diferencia das análises sociológicas e metafísicas das obras de arte. A pré-aparência é um conceito ontológico e não metafísico ou sociológico. Entretanto, como fragmento, as obras povoam nosso universo cultural significando e ressignificando aquilo que só pode ser pronunciado como pressentimento de uma ausência: como um "falta alguma coisa!". E, é na busca desse algo que falta que a arte se apresenta como transgressiva e utópica. Nesse sentido, podemos afirmar que a pré-aparência (Vor-Schein) artística como antecipação transgressiva é uma chave de leitura fundamental na compreensão da estética de Ernst Bloch.

\section{Referências}

BLOCH, Ernst. O principio esperança. Tradução de Nélio Schneider. Rio de Janeiro: EDUERJ: Contraponto, 2005. v. 1.

BLOCH, Ernst. Experimentum Mundi: Question, catégories de l'élaboration, praxis. Traduction et notes de Gerard Raulet. Paris: Payot, 1981.

$\mathrm{BLOCH}$, Ernst. Experimentum Mundi. Frage, Kategorien des Herausbringens, Praxis. Frankfurt am Main: Suhrkamp Verlag, 1985. (Gesamtausgabe, Band 15).

BLOCH, Ernst. Tübinger Einleitung in die Philosophie. Frankfurt am Main: Suhrkamp Verlag, 1985.

FREDRIC, Jameson. Marxism and Form: twentieth-century dialectical theories of literature. New Jersey: Princeton University Press, 1974.

FURTER, Pierre. Dialética da esperança. Rio de Janeiro: Paz e Terra, 1974.

HORNÄK, Sara. Espinosa e Vermeer: a imanência na filosofia e na pintura. Tradução de Saulo Krieger. São Paulo: Paulus, 2010
MACHADO, Carlos Eduardo Jordão. Um capitulo da história da modernidade estética: Debate sobre o expressionismo (Ernst Bloch, Hanss Eisler, Georg Lukács e Bertolt Brecht). 2. ed. São Paulo: Unesp, 2016.

MÜNSTER, Arno. Figures de l'utopie dans La pensée d'Ernst Bloch. Paris: Hermann Philosophie, 2009.

RAULET, Gérard. Utopie - Marxisme selon Ernst Bloch: un système de l'inconstructible. Paris: Payot, 1976.

UEDING, Gert. Blochs Ästhetik des Vor-Scheins. In: BLOCH, Ernst (hrsg.). Ästhetik des Vor-Scheins. Frankfurt/M: Suhrkamp Verlag, 1974. bd. 1.

UEDING, Gert. Tagtraum, künstlerische Produktivität und Werkprozeß. In: BLOCH, Ernst (hrsg.). Ästhetik des Vor-Scheins. Frankfurt/M: Suhrkamp Verlag, 1974. bd. 2.

UEDING, Gert. L'art comme utopie: remarques sur l'esthétique du pré-apparaître chez Ernst Bloch. In: RAULET, Gerard (ed.). Utopie - Marxisme selon Ernst Bloch: un système de l'inconstructible. Paris: Payot, 1976. p. 68-79.

VIDAL, Francesca. Kunst als Vermittlung von Welterfahrung. Zur Rekonstruktion der Ästhetik von Ernst Bloch. Würzburg: Königshausen \& Neumann, 1994.

VIDAL, Francesca. Ästhetik. In: DIESTSCHY, Beat; ZEILINGER, Doris; ZIMMERMANN Rainer (hrsg.). Bloch-Wörterbuch: Leitbegriffe der Philosophie Ernst Blochs. Berlin: De Gruyter 2012. p. 13-38.

ZIPES, Jack. Introduction: Toward a Realization of Anticipatory Illumination. In: BLOCH, Ernst. The Utopian Functon of Art and Literature: Selected Essays. Studies in contemporary German social thought. Cambridge, Mass.: MIT Press, 1988.

\section{Ubiratane de Morais Rodrigues}

Doutor em Filosofia pela Universidade de São Paulo (USP), em São Paulo, SP, Brasil. Professor Adjunto II de Filosofia da Universidade Federal do Maranhão (UFMA), em Grajaú, MA, Brasil.

\section{Endereço para correspondência}

Ubiratane de Morais Rodrigues

Universidade Federal do Maranhão

Av. Aurila Maria Santos Barros de Sousa, s/n

Loteamento Frei Alberto Beretta, 65940-000

Grajaú, MA, Brasil

Os textos deste artigo foram revisados pela Poá Comunicação e submetidos para validação do autor antes da publicação. 